selected OSA patients who cannot use CPAP or who wish a curative treatment without life-long dependency on these devices.

Abstract P265 Table 1 Table comparing Pre- and Post-Operative Ambulatory Sleep Study Results

\begin{tabular}{lccccc}
\hline $\mathbf{N = 8}$ & $\begin{array}{c}\text { Mean } \\
\text { Pre-surgery }\end{array}$ & $\begin{array}{c}\text { Range } \\
\text { Pre-surgery }\end{array}$ & $\begin{array}{c}\text { Mean } \\
\text { Post-surgery }\end{array}$ & $\begin{array}{c}\text { Range } \\
\text { Post- } \\
\text { surgery }\end{array}$ & \% Difference \\
\hline $\mathrm{AHI}(/ \mathrm{h})$ & 17.4 & $9-49.2$ & 4.58 & $0.4-13.1$ & 74 \\
$\begin{array}{l}\text { Oxygen } \\
\text { Desats }(/ \mathrm{h})\end{array}$ & 11.0 & $3.7-28.5$ & 3.45 & $0.1-9.6$ & 69 \\
\hline
\end{tabular}

\section{P266 RESPIRATORY, SLEEPINESS AND METABOLIC MEASURES AND OBSTETRIC OUTCOMES IN OBESE EXPECTANT MOTHERS}

doi:10.1136/thoraxjnl-2012-202678.358

J James, A K Datta. York Teaching Hospital, Hull York Medical School, York, UK

Increasing obesity in the UK population includes expectant mothers. ${ }^{1}$ Data from local antenatal clinics(3391 deliveries and 3826 women booked in 2011) show that the number of women with a BMI> 30 (O) and $\mathrm{BMI}>50(\mathrm{SO})$ are rising particularly in the last 5 years (Fig. 1). We wished to determine the respiratory consequences and maternal outcome for these women.
We examined obese women with a BMI $>50 \mathrm{Kg} / \mathrm{m}^{2}$ (SO) who gave birth in 2011 and matched them against non-obese (BMI <30) women $(\mathbf{N})$ who delivered on the same day. The percentage of $\mathbf{S O} v$ $\mathbf{N}$ women respectively who gave a history of asthma, diabetes and depression, was $67 \%$ v $17 \%, 50 \%$ v $0 \%$ and $50 \%$ v $17 \%$ respectively.

Mean Oxygen saturation in (O and SO) women, supine at rest and awake was $98 \%$ and in $\mathbf{N} 99 \%$. This difference was statistically significant ( $\mathrm{p}=0.016$, unpaired test, $26 \mathrm{df}$ ). Snoring was seen in $67 \%(\mathbf{O} \& \mathbf{S O})$ v $40 \% \mathbf{N}\left(\mathrm{p}=0.07, \chi^{2}\right)$. No difference was seen in the mean Epworth sleepiness scores (ESS; 0 6.2 v N 6.6) suggesting ESS is insensitive in these patients. Mean (range) heart rate at rest awake was 84.7 (72-106) bpm in $\mathbf{S O}$ and $\mathbf{O}, \mathbf{v} 81.5$ (70-99) in $\mathbf{N}$ ( $p=0.66$, unpaired $t$ test)

Mean (range) weight gain during pregnancy in $\mathbf{N}$ was 10 (1-16) $\mathrm{Kg} \vee 6.3(-5-20) \mathrm{Kg}$ in $\mathbf{S O}$ and $\mathbf{O}$ ( $\mathrm{p}=0.17$, unpaired t test). $100 \%$ $\mathbf{N}$ but only $67 \%$ SO women delivered babies with an acceptable birth weight defined as $2.7-4.0 \mathrm{Kg}$. $37.5 \%$ of $\mathbf{O}$ and $\mathbf{S O}$ women had miscarriages $\mathrm{v} 8.3 \% \mathbf{N}\left(p=0.066, \chi^{2}\right)$.

We conclude that obesity, particularly in SO, is associated with an increasing burden on the respiratory and psychological health of expectant mothers, on the outcome of their pregnancies and hospital services.

\section{Reference}

Heslehurst N, Ells LJ, Simpson H, Batterham A, Wilkinson J, Summerbell CD (2007)Trends in Maternal Obesity incidence rates, demographic predictors, and health inequalities in 36,821 women over a 15-year period. BJOG 114:187-94.

We acknowledge support of Consultant obstetricians, anaesthetists and Midwifery staff.
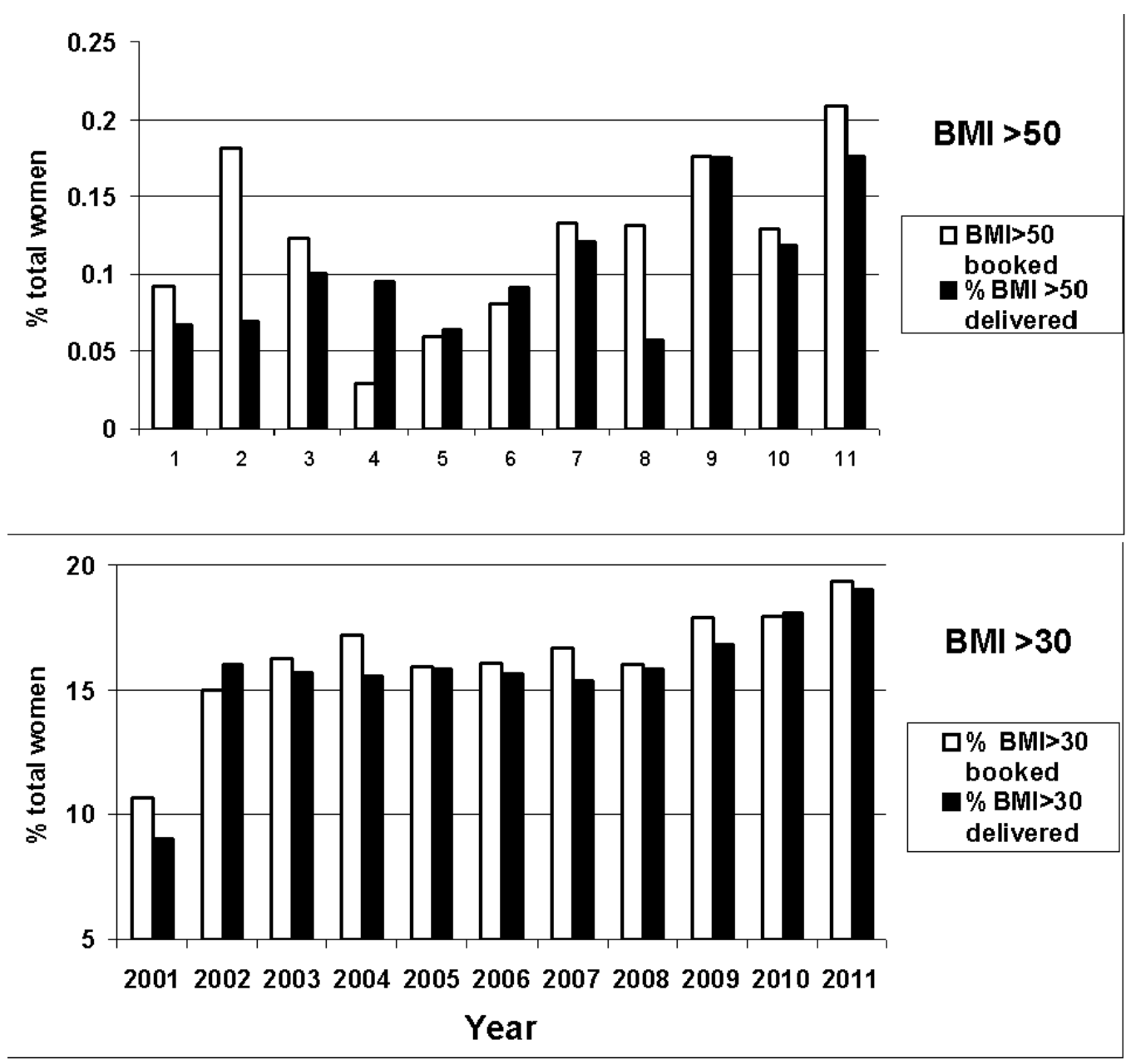

Abstract P266 Figure 1 